\title{
Need for Fracture Behavior based Designer Friendly Expressions for Fracture Energy and Minimum Flexural Reinforcement
}

\author{
T. Muralidhara Rao and T.D.Gunneswara $\mathrm{Rao}^{2}$ \\ 'CVR College of Engineering/Civil Engineering Department, Hyderabad, Indiat. \\ Email: tmuralidhararao@gmail.com \\ ${ }^{2}$ National Institute of Technology/Civil Engineering Department, Warangal. India. \\ Email: tdgtdg@gmail.com
}

\begin{abstract}
Present National and International codes of practice lead to a size invariant expression for minimum percentage of nexural reinforcement. But the influence of member size or fracture parameters namely, fracture energy and critical crack tip opening displacement are not considered. ACI 446.1R-91 (Re-approved 1999) strongly recommends application of fracture mechanics principles to quasi-brittle material like concrete. Detailed literature study is made on the influence of fracture energy, critical crack tip opening displacement, size of the member, compressive strength of concrete and yield strength of concrete on minimum flexural reinforcement of concrete members. Several researchers have proposed expressions for minimum flexural reinforcement of concrete members, but the review of literature on fracture behavior of lightly reinforced concrete members show contradiction in conclusions. Designer friendly expressions for fracture energy and minimum flexural reinforcement are essential to the practicing engineers to evaluate fracture energy and minimum flexural reinforcement without knowing about the RILEM standards.
\end{abstract}

Index Terms--- Fracture energy, Size effect, Effective length of fracture process zone, Compressive strength and Minimum flexural reinforcement.

\section{INTRODUCTION}

A certain minimum amount of reinforcement is necessary in any concrete member to impart adequate ductility. In this regard, codes of practice of different Nations have provided size invariant expressions for minimum flexural reinforcement to be maintained in the concrete members. Standard codes of practice have considered the minimum flexural reinforcement as dependent on either compressive strength of concrete or yield strength of steel. A detailed review of literature on minimum flexural reinforcement of reinforced concrete members is presented.

\section{LITERATURE REVIEW ON MINIMUM FLEXURAL REINFORCEMENT OF CONCRETE MEMBERS}

Bosco et al [1990] reported experimental studies on $30 \mathrm{RC}$ beams made of concrete of average compressive strength $91 \mathrm{Mpa}$. The beams were reinforced in such a way that they fall in five different classes with respect to the brittleness number. It was found that beams of same brittleness number revealed same variation in load- same variation in load-deformation irrespective of the beam depth and the area of steel.

Bosco et al [1990] used the experimental loaddeformation variations for defining minimum flexural reinforcement in high strength concrete (HSC) beams. A transitional brittleness number was defined when a change in the behavior of beams occurred from brittle to ductile, which corresponds to $\rho_{\min }$.

Ananthan et al [1990] developed a model to determine the influence of strain softening in concrete beams. Softening beam theory was used in the model development. The size effects were determined by using an empirical equation for the fracture process zone derived from the experimental results available in literature. A linear stress-strain relationship in the post-peak region was used.

Bosco et al [1992] conducted experiments on 46 more beams with five different strengths ranging from 16-76 Mpa to calculate the transitional brittleness number $\mathrm{Np}$, which defines a change in the behavior from brittle to ductile. Reinforcement corresponding to that was defined as rho min. Based on experimental data, an expression for minimum flexural reinforcement was proposed:

$$
\rho_{\text {min }}=\frac{K_{s c}\left(0.1+0.0023 f_{c}\right)}{f_{,} \sqrt{D}}
$$

Baluch et al [1992] combined the concepts of fracture mechanics as well as constitutive relations and strain variations to arrive at a theoretical model for prediction of residual strength of $\mathrm{RC}$ beams. The crack propagation with increase in the moment was predicted using the 
theoretical model and validated with experiments. The model was used for a crack controlled design. The design moment and the crack depth are the design parameters. A criterion was proposed for minimum flexural reinforcement to avoid unstable crack propagation. The moment corresponding to the maximum load of reinforced concrete beam is greater than the initial cracking moment of a plain concrete beam. The expression for minimum flexural reinforcement is:

$$
\rho_{\min }=\frac{1.9134 K_{/ C}^{0.82}}{f_{y}^{0.9922\left(1.7-\frac{2.6 C}{D}\right)}}
$$

Gerstle et al [1992] studied the tensile cracking behavior of singly reinforced concrete beams in flexure using the fictitious crack model. An analytical model was proposed by considering the equilibrium of tensile and compressive forces and deformation of concrete. An expression for minimum reinforcement was defined but it does not contain the yield stress of reinforcement, $\mathrm{f}_{\mathrm{y}}$ which was objected by many researchers.

$\rho \min =\left(\frac{E_{c}}{E_{s}}\right)\left(\sqrt{0.0081+0.0148 \frac{f_{s} D}{E_{c} w_{c}}}-0.09\right)^{\frac{1}{2}}$

Wafa F. F. and Ashour S.A. [1993] presented experimental results of 20 high strength concrete beams tested in flexure to examine minimum flexural reinforcement requirement without fracture mechanics principles. The variables were flexural reinforcement ratio and concrete compressive strength. The flexural reinforcement ratio ranging from 0.21 to $0.88 \%$, and the 28 day concrete compressive strength ranging from 45 to 90 $\mathrm{MPa}$ were considered. The test results were compared with the minimum reinforcement ratios of both the ACI: $318-89$ and ACI: 318-95 Codes. Effects of specimen size and fracture parameters were not considered in this paper.

Ruiz et al [1998] performed experimental studies on lightly reinforced beams in which the importance of concrete cover and bond between steel and concrete on the behavior of RC beams was described. Beams with a large cover showed a secondary peak between concrete cover and steel yielding, which provides a hint as to the role of reinforcement cover in crack propagation.

M.Bruckner and R.Eligehausen [1998] research results suggest that minimum reinforcement ratio dependent on size of the member. The experiments on beams with depths varying from $0.125 \mathrm{~m}$ to $0.5 \mathrm{~m}$ and with $0.15 \%$ of reinforcement revealed that the load-deformation curves of these beams showed a large plateau after the peak load indicating very ductile behavior. It was observed that with increase in beam size, the brittleness increased. The need for a size-dependant definition of minimum reinforcement was emphasized. The value of, $\rho_{\mathrm{mtn}}$ is obtained by solving the following condition

$$
\rho_{\min } \geq \frac{M}{b d(d-0.5 \gamma x) f_{y}}<\rho_{b a l}
$$

Ashour S.A. [2000] tested nine reinforced highstrength concrete beams to investigate the effect of concrete compressive strength and flexural tensile reinforcement ratio on load-deflection behavior and displacement ductility of cracked rectangular reinforced concrete beams. Concrete compressive strengths of 48,78 , and $102 \mathrm{MPa}$ and tensile reinforcement ratios of $1.18,1.77$, and $2.37 \%$ were used. Displacement ductility was investigated and it was found that for a displacement ductility index of 3 , the ratio $\rho / \rho_{t}$ should not exceed 0.25 and 0.50 for concrete beams with concrete compressive strength of 102 and $48 \mathrm{MPa}$.

Iyengar K.T.S.R. et al [2002] used fictitious crack model to model the propagation of cohesive cracks in a beam of quasi-brittle material such as concrete. The stressdisplacement relation was assumed as a generalized power law function. Expressions for moment-rotation relations were given. The analysis gives the effect of the softening exponent on the size effect and snapback behavior of beams. The effect of the elasticity co-efficient of the central elastic layer on moment-rotation relation was also determined.

Shamu et al [2004] performed fracture studies on reinforced concrete beams based on bi-linear tension softening response of concrete. The proposed model predicts the minimum reinforcement in flexure as well as the crack width in $\mathrm{RC}$ beams.

Raghu Prasad et al [2005] considered strain softening of concrete in tension along with fracture mechanics principles. An improved model based on fundamental equilibrium equation for progressive failure of plain concrete beam was presented and extended for lightly reinforced concrete beam.

Fantilli A.P et al [2005] experimentally investigated the transition from the un-cracked to the cracked phase in lightly reinforced concrete beams by testing five full-scale beams under three-point bending. All beams had the same dimensions and the same percentage of flexural reinforcement. But the diameters of bars and the number of bars used are varied. Test results demonstrate that during the growth of crack, the moment rotation diagrams, the tensile strains in concrete and the shape of crack profiles depend on the mechanical response of bar diameter.

Kumar S. and Barai V. S. [2008] presented finite element formulation of cohesive crack model for predicting non-linear Mode-I fracture behaviour of geometrically similar notched plain concrete beams. The effect of finite element mesh on load bearing capacity of the beam was further analyzed. It was shown that for normal size-range structures, the values of peak load determined using the concept of linear elastic fracture mechanics deviates from those obtained using cohesive crack model. Influence of some important softening functions of concrete on the global response and size-effect curve was also presented. 
Carpinteri. A et al [2010] presented a new fracture mechanics based model for the analysis of reinforced concrete beams in bending describing both cracking and crushing growths taking place during the loading process by means of the concept of strain localization. The nonlinear behaviour of concrete in compression is modelled by the Overlapping Crack Model. On the basis of different nonlinear contributions due to concrete and steel, a numerical finite element algorithm is proposed. According to this approach, the flexural behaviour of reinforced concrete structural elements is analyzed by varying the main geometrical and mechanical parameters. It is concluded that the ductility is an increasing function of the compression steel percentages, the concrete compressive strength, the stirrups contents, whereas it decreases as the tensile steel percentage and/or the structural dimension increase.

\section{Significance Of Present Study}

In the near future, there is going to be a gradual change in the design methodology from the strength based design to fracture based design. And in this, fracture energy of concrete and minimum flexural reinforcement play a vital role. When the concrete strength increases to high strength levels, its fracture properties also change. While designing a structure using high strength concrete, the designer usually ignores the altered properties of concrete and possible changes in the overall response of the structure, because of the lack of adequate information in the present codes of practice.

In view of the safe design of structures, it is essential to develop designer friendly expressions for quantifying the fracture energy and minimum flexural reinforcement, which will be very useful to the practicing engineers. By using such formulae, laborious testing can be avoided to estimate them. If such formulae are developed, then the Practicing engineers need not know what the RILEM standards are and how to implement them in the field to evaluate the fracture energy of concrete.

\section{Discussion ON Literature FINDINGS}

On the basis of minimum reinforcement expressions suggested by different researchers, the following conclusions are made.

1) According to the minimum percent flexural reinforcement expressions given by Bosco et al, Ruiz et al and Hawkins et al, the minimum percent flexural reinforcement is found to be decreasing with the increase in size of the beam for a given compressive strength of concrete.

The minimum percent flexural reinforcement is observed as increasing with the increase in the compressive strength of concrete. As per Bosco et al, Ruiz et al and Hawkins et al, when the compressive strength of concrete is increased from $20 \mathrm{Mpa}$ to $30 \mathrm{Mpa}$, the percent increase in minimum flexural reinforcement for $200 \mathrm{~mm}$ depth beam is $15.77 \%$,
$27.18 \%$ and $25.49 \%$ respectively and the percent increase in minimum flexural reinforcement for $1000 \mathrm{~mm}$ depth beam is $15.8 \%, 28.91 \%$ and $25.51 \%$ respectively. For a compressive strength of $20 \mathrm{MPa}$, the percent decrease in minimum flexural reinforcement when the beam depth is varied from $200 \mathrm{~mm}$ to $1000 \mathrm{~mm}$ is $55.29 \%, 21.45 \%$ and $25.19 \%$ respectively. The variation of minimum reinforcement with size of beam for different compressive strengths of concrete is presented in Fig. 1. Fig. 2 and Fig. 3 respectively.
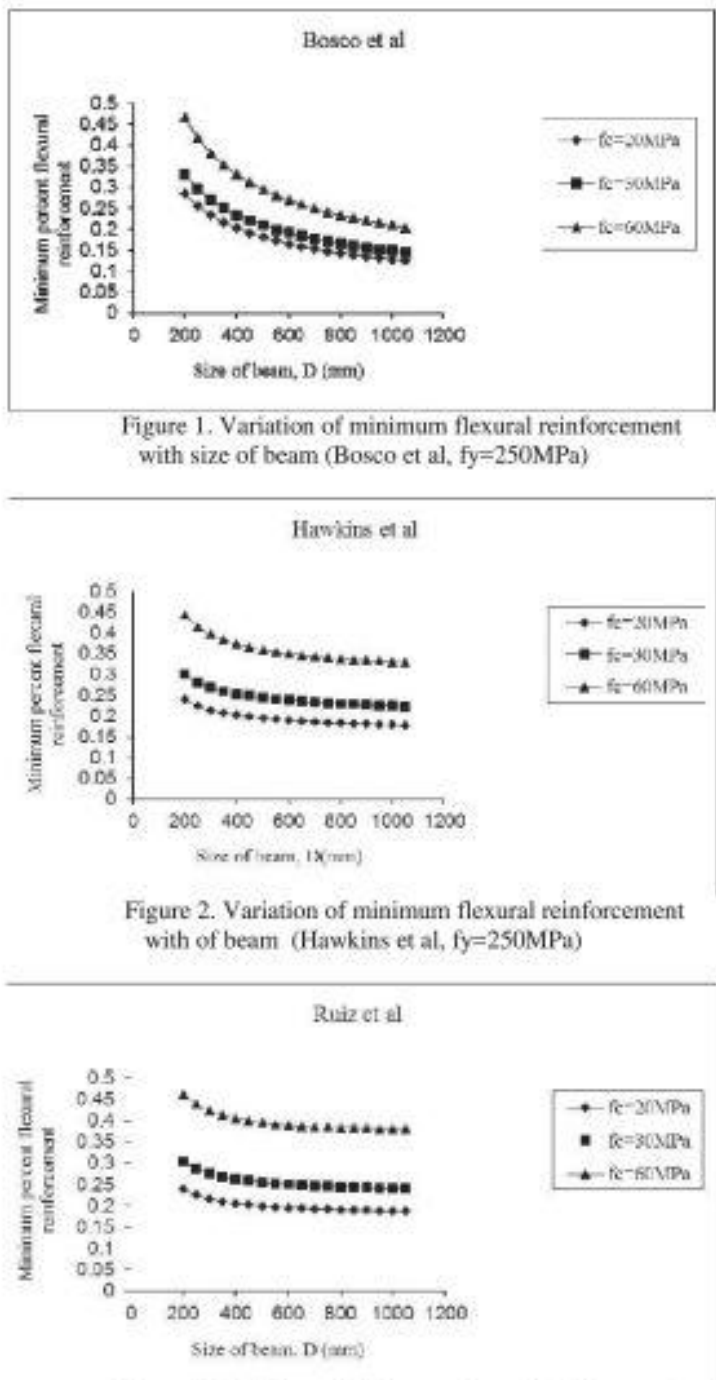

Figure 3. Variation of minimum flexural reinforcement with size of beam (Ruiz et al, fy=250MPa)

2) The findings of Bosco et al, Hawkins et al, Ruiz et al reveal that the minimum percent flexural reinforcement decreases with the increase in size of the beam for a given yield strength of steel. It is also observed that the minimum percent flexural reinforcement decreases with the increase in the yield strength of steel. For $200 \mathrm{~mm}$ depth of beam with $f y=250 \mathrm{Mpa}$, the percent decrease in minimum percent flexural reinforcement between Bosco et al and Hawkins et al is $16.43 \%$ and the Bosco et al and Ruiz et al is $16.36 \%$. 
For $200 \mathrm{~mm}$ depth of beam with $\mathrm{f}_{y}=415 \mathrm{Mpa}$, the percent decrease in minimum percent flexural reinforcement between Bosco et al and Hawkins et al is $16.43 \%$ and the Bosco et al and Ruiz et al is $18 \%$. For $200 \mathrm{~mm}$ depth of beam with $\mathrm{f}_{\mathrm{y}}=500 \mathrm{Mpa}$, the percent decrease in minimum percent flexural reinforcement between Bosco et al and Hawkins et al is $16.44 \%$ and the Bosco et al and Ruiz et al is $18.4 \%$. The variation of minimum reinforcement with size of beam when yield strength of steel increased is presented in the Fig. 4, Fig. 5 and Fig. 6 respectively.

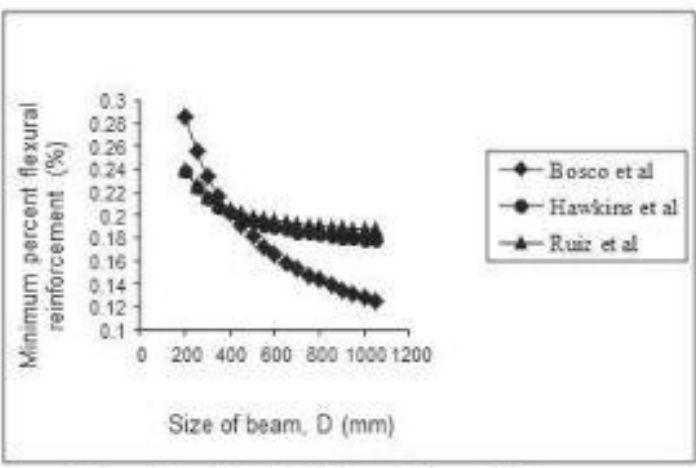

Figure 4. Variation of minimum flexural reinforcement with yield stress of steel $\left(\mathrm{f}_{3}=250 \mathrm{MPa}\right)$

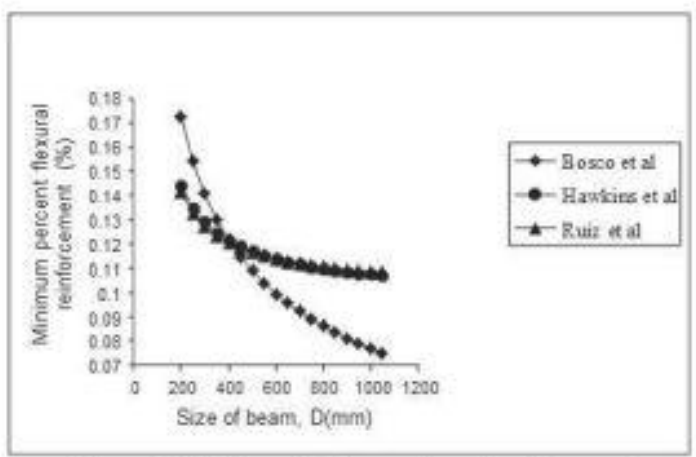

Figure 5. Variation of minimum flexural reinforcement with yield stress of steel $\left(f_{2}=415 \mathrm{MPa}\right)$

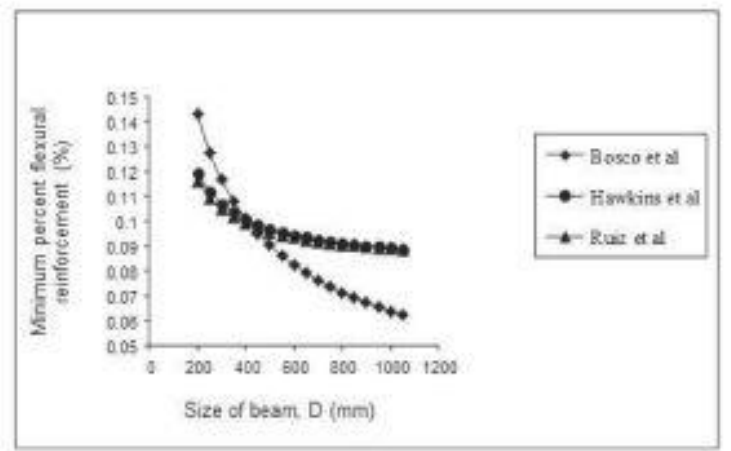

Figure 6. Variation of minimum flexural reinforcement with yield stress of steel $\left(\mathrm{f}_{\mathrm{y}}=500 \mathrm{MPa}\right)$

3) According to Bosco et al, Hawkins et al, Ruiz et al, the minimum reinforcement is found to be increasing with the increase in compressive strength of concrete for a given size of beam. The percent increase in minimum flexural reinforcement for $20 \mathrm{MPa}$ compressive strength of concrete in Bosco et al and Hawkins et al and Bosco et al and Ruiz et al is $16.43 \%$ and $18 \%$ respectively. The percent increase in minimum flexural reinforcement when the compressive strength of concrete is varied from $20 \mathrm{MPa}$ to $100 \mathrm{MPa}$ in Bosco et al, Hawkins et al, and Ruiz et al is $55.76 \%, 59.4 \%$ and $61.18 \%$ respectively.

The variation of minimum reinforcement with compressive strength of concrete is presented in Fig. 7.

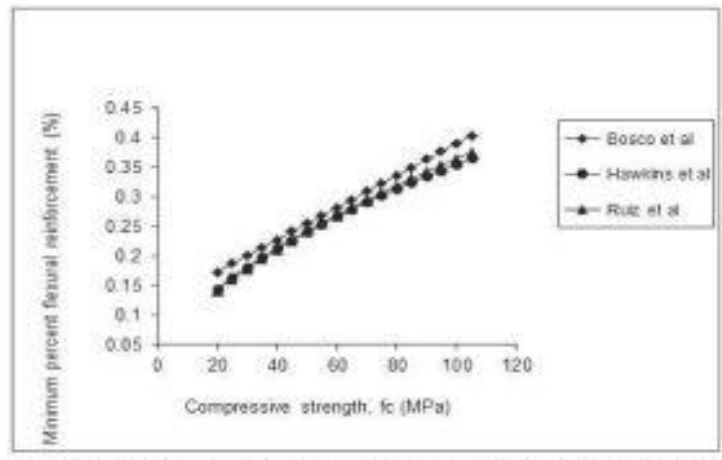

Figure 7. Variation of minimum flexural reinforcement with differen compressive strengths of concrete (fy $=250 \mathrm{MPa}$ )

4) Minimum percent flexural reinforcement predicted by Baluch et al is very high compared to the minimum reinforcement predicted by the other researchers, Bosco et al, Hawkins et al and Ruiz et al. For $f_{y}=250 \mathrm{MPa}$ and $\mathrm{f}_{\mathrm{c}}=20 \mathrm{MPa}$, minimum reinforcement variation with increase in size of beam is presented in the Fig. 8 . It is found that the minimum percent reinforcement decreases with the increase in size of the beam.

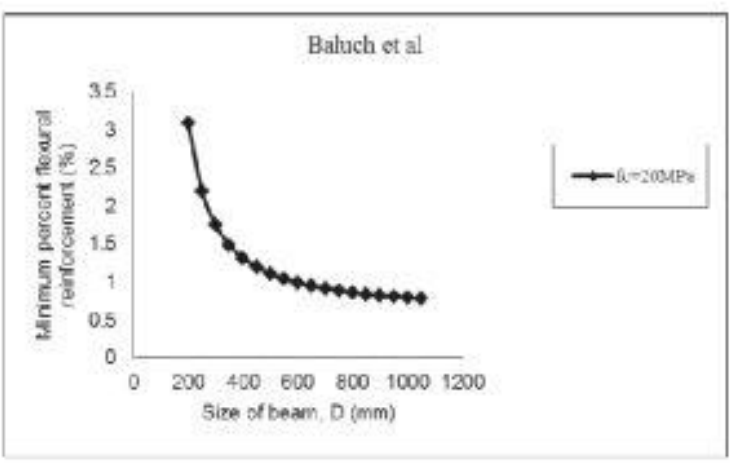

Figure 8. Variation of minimum flexural reinforcement with different compressive strengths of concrete ( $\left.f_{y}=415 \mathrm{MPa}\right)$

5) For a particular compressive strength of concrete, Gerstle et al prediction of minimum reinforcement variation with increase in size of beam is entirely different from the trend shown by other researchers, Bosco et al, Hawkins et al, Ruiz et al and Baluch et al. Minimum reinforcement variation with the increase in size of beam for compressive strengths of concrete, $20 \mathrm{MPa}, 30 \mathrm{MPa}$ and $60 \mathrm{MPa}$, is presented in Fig. 9. It is found that the minimum percent flexural reinforcement increases with the increase in size of beam when compressive strength of concrete is increased. According to Gerstle et al, when the compressive strength 
of concrete is increased from $20 \mathrm{Mpa}$ to $30 \mathrm{Mpa}$, the percent increase in minimum flexural reinforcement for $200 \mathrm{~mm}$ depth beam is $11.08 \%$ and the percent increase in minimum flexural reinforcement for $1000 \mathrm{~mm}$ depth beam is $9.45 \%$.

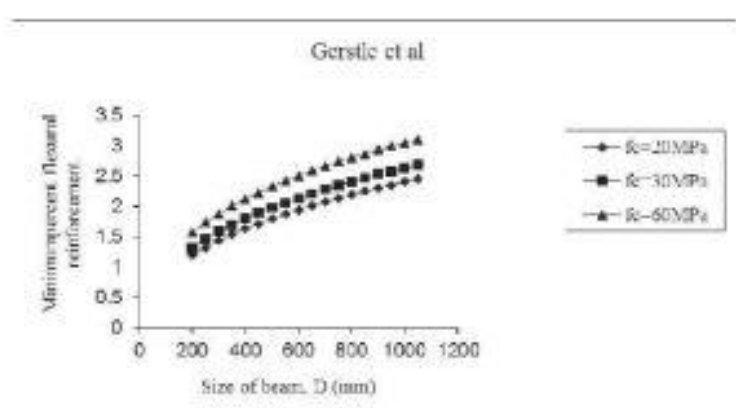

Figure 9. Variation of minimum flexural reinforcement with compressive strength of coacrete $\left(\mathrm{f}_{\mathrm{y}}=250 \mathrm{MPa}\right)$

The minimum reinforcement expressions given in the present National and International codes of practice like BIS: $456-2000$, ACI: $318-2007$ and BS: $8110-2003$ are dependent on either yield stress or compressive strength of concrete or only the tensile strength of concrete. Hence, the codes of practice are giving a minimum reinforcement value which is invariant of size of the member, where as in case of AS: $3600-2005$, the minimum reinforcement expression consists of size of the member. But no-where in code it is mentioned whether fracture mechanics size effect is considered or not. The minimum reinforcement expressions by BIS, ACI, BS and AS are given in Table 1. The minimum reinforcement as per AS: $3600-2005$ is decreasing with the increase in the size of the specimen. The variation of minimum reinforcement with the size of member is presented in Fig. 10.

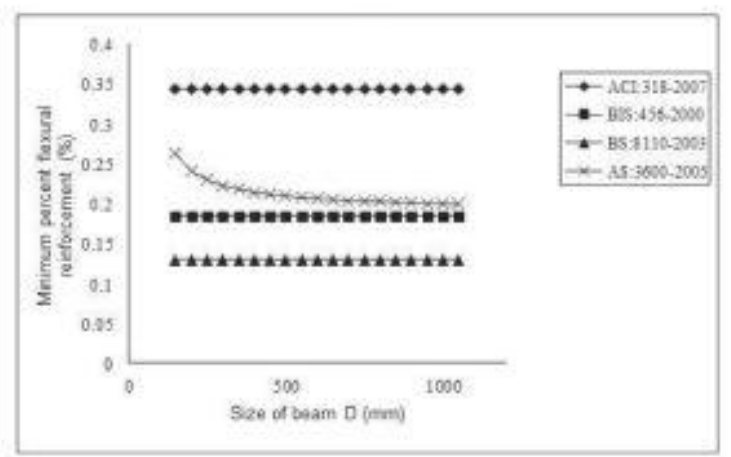

Figure 10. Variation of minimum flexural reinforcement with size of beam as per present codes of practice
Table 1. Minimum reinforcement expressions by National and International codes of Practice

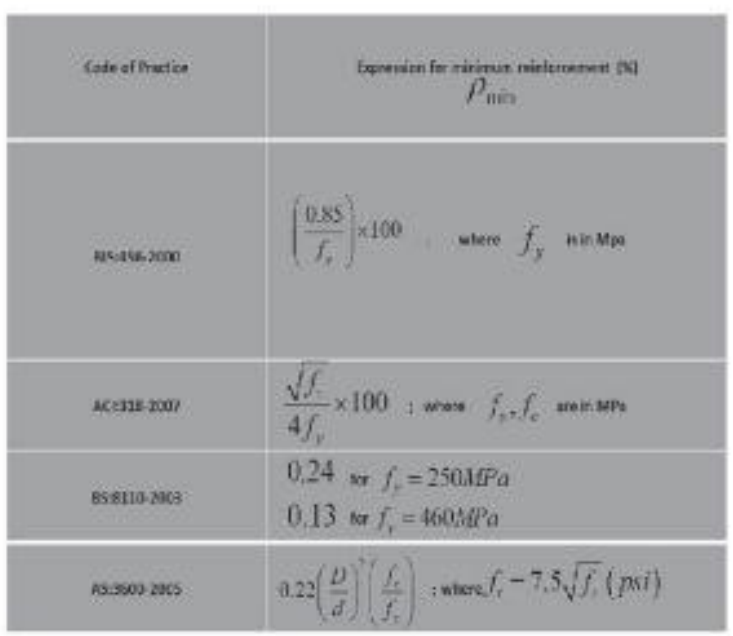

\section{Conclusions}

1. A detailed review of literature on the behavior of lightly reinforced concrete members showed contradiction of conclusions. Bosco et al [1992] in

their studies indicated a decrease in minimum steel ratio with the increase in beam height ( $h$ ) in the proportion of $h^{-0.50}$. The study of Hawkins et al [1992] and Baluch et al [1992] indicated the variation of minimum reinforcement with size as $h^{-0.167}$ and $h^{-0.8511}$ respectively. Studies by Gerstle et al [1992] showed minimum reinforcement ratio variation with size as $h^{0.4083}$ whereas Ruiz et al [1996] predicted the variation of minimum steel ratio with size as $h^{-0.1382}$.

2. Based on literature study, it is felt that:

i. Can an analytical model be developed for estimating the minimum flexural strength of $\mathrm{RC}$ as well as high strength concrete?

ii If so, how to quantify the fracture energy of normal as well as high strength concrete?

iii. Can an expression for minimum flexural reinforcement be obtained using the analytical data developed in (i) and (ii) knowing the compressive strength of concrete, yield strength of reinforcing bars and fracture energy of concrete?

iv. Whether the expressions developed in (iii) stands valid or not.

3. In near future, there is going to be a gradual change in the design methodology from strength based design to the fracture based design. And in this, fracture energy of concrete and the minimum flexural reinforcement play a vital role. In view of the above, it is necessary to develop designer friendly expressions for quantifying the fracture energy and minimum flexural reinforcement, which will be very useful to the practicing engineers. 


\section{REFERENCES}

[1] Bosco C., Carpinteri, A and Debernardi P G., Fracture of reinforced concrete:Scale effects on snap-back instability, Engineering Fracture Mechanics, 35 (4), 1990, pp 665-677.

[2] Ananthan H., Raghuprasad B. K., Sundara Raja Iyengar K. T., Influence of strain softening on fracture of plain concrete beams, Int. Journal of Fracture 1990; 45:195-219.

[3] Bosco C. and Carpinteri, A., Fracture behaviour of beam cracked across reinforcement, Theoretical and Applied Fracture Mechanics, 17 (2), 1992, pp 61-68.

[4] Baluch, M.H., Azad A.K. and Ashmawi, W., Fracture Mechanics Application to Reinforced Concrete Members in Flexure, Proc International Workshop on Applications of Fracture Mechanics to Reinforced Concrete, Italy, 1992, pp 413-436.

[5] Gerstle, W.H., Dey, P.P., Prasad, N.N.V., Rahulkumar, P. and Xie, M., Crack growth in flexural members-A fracture mechanics approach, ACI Structural Journal, 89 (6), 1992, pp 617-625.

[6] Wafa, F.F. and Ahour, S.A., Minimum flexural reinforcements of high strength beams, SP: 172-30. ACI Structural Journal, 90(3),1993,pp 279-87.

[7] Ruiz, G., Elices, M., and Planas, J., Size effect and bond-slip dependence of lightly reinforced concrete beams-Minimum reinforcement in concrete members, A. Carpinteri, ed., Elsevier, London, 1998, pp 67-97.

[8] Bruckner, M., and Eligehausen, R., Minimum reinforcement in RC Beams, $2^{\text {nd }}$ Int. Ph.D. Symposium in Civil Engineering 1998 Budapest, 1-7, 1998.

[9] Ashour. S.A., Effect of compressive strength and tensile reinforcement ratio on flexural behavior of high-strength concrete beams, Journal of Engineering Structures, 22, 2000, pp 413-423.

[10] lyengar, K. T. S. R., Raviraj, S. and Jayaram, T. N., Analysis of crack propagation in strain-softening

\section{NOTATIONS}

D Total depth of member

$\mathrm{w}_{\mathrm{c}} \quad$ Critical Crack Opening Displacement

$\mathrm{K}_{\mathrm{IC}}$ Critical Stress Intensity Factor

(Fracture Toughness)

b Width of member

$f_{t} \quad$ Material tensile strength

$\mathrm{E}_{c} \quad$ Modulus of Concrete

$\rho_{\min }$ Minimum flexural reinforcement

$f_{y} \quad$ Yield Strength of Steel

$\mathrm{C}_{8}$ Cover to tension steel

A ${ }_{s t}$ Area of Steel

f. Characteristic Compressive

Strength of Concrete

$\mathrm{E}_{\mathrm{s}} \quad$ Modulus of Steel

$\gamma \quad$ Stress block parameter

$x \quad$ Neutral axis depth

Poal Balanced steel ratio

M Moment corresponding to first crack beams, Engineering Fracture Mechanics, 69, 2002, pp761-778.

[11]Shamu, S., Rao, C. L. and Menon D., Fracture in reinforced concrete beams, STTP, Fracture Mechanics of Concrete: Theory and Applications, 2004, Madras, India.

[12]Raghu Prasad, B.K., Bharatkumar, B.H., Murthy, D.S.R., Narayanan, R. and Gopalakrishnan, S., Fracture mechanics model for analysis of plain and reinforced concrete high performance beams, Journal of Engineering Mechanics, 131 (8), 2005, pp 831-838.

[13] Fantilli, A. P., Ferretti, D., Iori, I., and Vallini, P. Behaviour of $\mathrm{R} / \mathrm{C}$ elements in bending and tension: the problem of minimum reinforcement ratioMinimum reinforcement in concrete members, A.Carpinteri, ed., Elsevier, London, 2005, pp 99-125.

[14] Belgin,C.M., Siddik Sener, Size effect on failure of Over reinforced concrete beams, Engineering Fracture Mechanics, $10^{\text {th }}$ Sept, 2007.

[15] Kumar, S., and Barai, V.S., Cohesive crack model for the study of Non-linear fracture behaviour of concrete, Indian Concrete Institute, Volume 89, November 2008 , pp 7-15.Carpinteri, A., Corrado,M., and Paggi,M., An integrated cohesive/overlapping crack model for the analysis of flexural cracking and crushing in RC beams, International Journal of Fracture, 2010, pp.161173.

[16]AS: 3600-2005, Australian Standard for Concrete Structures, Standards Australia, Sydney.

[17] BIS: 456-2000, Code of practice for design of plain and reinforced concrete structures, Bureau of Indian Standards, New Delhi.

[18] BS: 8500-2003, British Standard Code of Practice for Structural Use of Concrete, Part II, British Standards Institute, London.

[19] L.Elfgren, Fracture mechanics of concrete structures from theory to applications, RTA 90-FMA fracture mechanics to concrete-application RILEM, Chapman and Hall, 1989, London. 